

\title{
Joint maintenance-inventory optimisation of parallel production systems
}

\author{
Farhad Zahedi-Hosseini ${ }^{1}$, Philip Scarf ${ }^{2 *}$ and Aris Syntetos ${ }^{3}$ \\ ${ }^{1}$ School of Computing, Science and Engineering, University of Salford, Manchester M5 4WT, UK \\ ${ }^{2}$ Salford Business School, University of Salford, Manchester M5 4WT, UK \\ ${ }^{3}$ Panalpina Centre for Manufacturing and Logistics Research, Cardiff Business School, Cardiff University, \\ Cardiff CF10 3EU, UK \\ *corresponding author
}

\begin{abstract}
We model a joint inspection and spare parts inventory policy for maintaining machines in a parallel system, where simultaneous downtime seriously impacts upon production performance and has a significant financial consequence. This dependency between system components means that analysis of realistic maintenance models is intractable. Therefore we use simulation and a numerical optimisation tool to study the cost-optimality of several policies. Inspection maintenance is modelled using the delay-time concept. Critical spare parts replenishment is considered using several variants of a periodic review policy. In particular, our results indicate that the cost-optimal policy is characterised by equal frequencies of inspection and replenishment, and delivery of spare parts that coincides with maintenance intervention. In general, our model provides a framework for studying the interaction of spare parts ordering with maintenance scheduling. The sensitivity analysis that we present offers insights for the effective management of such parallel systems, not only in a paper-making plant, which motivates our modelling development, but also in other manufacturing contexts.
\end{abstract}

Keywords: maintenance; inventory; parallel production; delay-time; spare parts; simulation.

\section{Introduction}

The optimisation of maintenance operations offers economic benefits [1] and therefore maintenance is increasingly highlighted as an integral part of production and business in both the research literature [2] and the practitioner literature [3]. Typically, in the literature, a maintenance interval that yields the minimum cost is determined assuming infinite availability of spare parts [4]. This implies that spares are either highly standardized and readily replenished, or so inexpensive that large quantities can be stored. However, in reality, spares are often highly customized and their procurement lead-time is relatively long [5]. Therefore, maintenance analysis and decision-making [6] without the consideration of spare parts inventory may result in sub-optimal decisions.

The literature on joint modelling of maintenance and spare parts inventory is developing rapidly. However, little of this research considers systems with two or more machines, operated in parallel [7]. Indeed Van Horenbeek et al. [8] state that single-machine systems are oversimplified and do not reflect the interactions in real manufacturing systems. Scarf [9], in an "appeal to maintenance modellers to work with maintenance engineers and managers on real problems", acknowledges that "too much attention is paid to the invention of new models, with little thought, it seems, as to their applicability". This latter observation remains valid since evidence suggests that little research on the optimisation of maintenance is applicable to real industrial systems [10].

We aim to address these shortcomings in our study, and we model the maintenance and spare parts inventory of an industrial plant comprising two parallel machines. In this context, an important 
objective of maintenance is the elimination, or at least minimisation of simultaneous downtime. In this way, we suppose that simultaneous downtime has serious consequences for the performance of production and upstream and downstream processes. Note, this is in contrast to say offshorewindfarm maintenance [11], where opportunistic maintenance of wind turbines in parallel is ideal in order to minimise significant set-up costs [12].

Viewed separately, maintenance models broadly fall into two sets: time-based, including blockreplacement and age-based replacement [13]; and condition-based [14.15], including models of periodic inspection whereby only those components that are defective are replaced. An inspection policy, provided it is effective [16], offers a cost advantage over time-based policies where items are replaced regardless of their condition or state. The classic model of inspection maintenance is the delay-time model [17], reviewed by Wang [18], developed by many ([19-22]), and used in case studies (e.g. [23]). We shall use the delay-time model in our study and suppose that the parallel machines are subject to regular inspections that aim to identify defects and carry out consequent replacements.

We consider our inspection policy in conjunction with a periodic review replenishment policy. We choose this particular inventory policy because the inventory literature (e.g. [24]) and previous research studies [25] suggest that this policy complements a periodic maintenance policy. Shared inventory imposes a logistical interaction between the machines in the parallel system, so that in principle we model a multi-component system with dependence. Further logistical interaction arises because we suppose that the costs of individual machine downtimes are not additive, in that simultaneous downtime of machines incurs a severe penalty. These logistical dependencies are distinct from economic dependence that arises from shared set-up costs for maintenance interventions [26].

The joint policy is considered in two variants. In these variants, the timing of orders may be such that spare parts delivery coincides with inspection (just-in-time ordering) or ordering itself coincides with inspection (coincident ordering). Further, the frequency of inspection and the frequency of replenishment may be the same or different.

The joint optimisation of maintenance and inventory is reviewed in [8] and this review is updated in [25]. Therein, there exist studies of joint optimisation of inspection and spare parts inventory that use the delay-time model [25,27,28], and that do not [5,29], but these do not consider parallel machines. On the other hand, studies that do consider parallel machines do not consider joint optimisation of maintenance and inventory [30]. There exist studies of joint optimisation for single-component systems [31,32], but these are for series systems, and there are studies of joint policies that do not consider inspection (joint block replacement policies are studied in [10,33-40], and joint age-based replacement policies are studied in [32,41]). Furthermore, studies of joint inventory and condition-based policies exist $[42,43]$, but these studies do not consider parallel lines. Therefore, as far as we are aware, our paper is the first to consider joint optimisation of maintenance and spare parts for parallel production systems.

Finally, turning to solution methodology, the use of simulation to analyse joint policies is common for realistic settings [33,37,44-46]. Simulation has the flexibility to address the increasingly complex and dynamic nature of maintenance optimisation, and inventory optimisation adds to this complexity.

The layout of the paper is as follows. The next section describes the context that motivates our model. In Section 3, we describe the maintenance and inventory policies and their assumptions, and the cost structure of the joint policy. Our simulation methodology is described in Section 4. Section 
5 presents the results and discussion of these, and also includes a sensitivity analysis of the policy to model parameters. We finish with concluding remarks.

\section{Problem description}

The specific industrial situation considered is a paper mill consisting of two machines working in parallel. Beside relatively low-cost cutting blades, bearings are the critical components in this plant. Bearings are used extensively in paper-making machines and, apart from general risks to safety, their failure can incur costs due to repair or replacement, and unplanned machine downtime. Folger et al. [47] describe several conditions under which bearings can fail unexpectedly and catastrophically, and Jacobs et al. [48] and Collins [49], for example, describe engineering models of bearing life (e.g. the "L10-life"). The notion of the L10-life is consistent with the three-state failure model that we use for bearing life, whereby a bearing degrades from the good to the defective to the failed state. A bearing operates when it is defective and the defective state is revealed only by inspection. This is the delay-time concept, and the sojourns in the good and defective states are random variables. The sojourn in the defective state is called the delay-time, and is similar to the notion of the $P-F$ (potential to functional failure) interval in reliability-centred maintenance [50,51].

We suppose a common inventory exists for bearings for both machines. Paper machinery typically have many identical bearings. In our model, it is supposed that inventory planning is concerned only with these bearings. That is, inventory control for a single stock keeping unit will be considered.

The delay-time model implies that failures occur at random times and that at inspection a random number of defects will be found. Thus, despite that inspection times are known, the times of demands for spare parts are unknown. Consequently, when, relative to inspection, and in what quantity spares should be ordered is an interesting question.

Survey data [45] provide information about: possible defect arrival patterns, delay-times, and their distributions; inspections; preventive replacements; failure replacements; current maintenance and replenishment policies for replacing critical components; lead-times; and costs. The data were provided by maintenance and inventory control experts and paper manufacturers, who completed a questionnaire on their experience of paper making machinery and the critical components therein. This ensured that the model and simulation experiments were realistic and not based on some arbitrary data. This process also ensures that our modelling approach is relevant to other (similar) settings. Furthermore, variability in the values of model parameters was quantified in order to reflect a range of opinion about maintenance "inputs and outputs" where it existed. We also used [28], in which maintenance optimisation for a paper-making plant is also considered, to guide model parameter specification. The values and ranges of model parameters are given in the relevant sections.

\section{The joint maintenance and spare parts inventory model}

\subsection{Notation}

$C_{d(\text { ind })}$ Cost-rate of individual machine downtime

$C_{d(\text { sim })}$ Cost-rate of simultaneous machine downtime

$C_{f} \quad$ Cost of a failure replacement (per item) 
$C_{r} \quad$ Cost of a preventive replacement (per item)

$C_{h} \quad$ Cost-rate of inventory holding

$C_{i} \quad$ Cost of an inspection

$C_{m} \quad$ Cost-rate of one maintenance technician

$C_{o} \quad$ Cost of an order including delivery

$C_{s h} \quad$ Cost of an emergency order including delivery

$C_{u} \quad$ Cost of one item (unit cost of a bearing)

$C_{\infty} \quad$ Long-run total cost per unit time, or cost-rate

$d_{f} \quad$ Downtime due to a failure replacement

$d_{r} \quad$ Downtime due to a preventive replacement

$D_{\infty} \quad$ Long-run total downtime per unit time, or downtime-rate

$L_{o} \quad$ Normal delivery lead-time

$L_{s h} \quad$ Emergency delivery lead-time

$R \quad$ Order review period; a decision variable

$S \quad$ Order-up-to level; a decision variable

$T \quad$ Inspection interval; a decision variable; $T=k R$, for $k>0$

$U \quad$ Time-to-defect arrival; initial time from new (or as new) until a defect that could be identified by inspection arises; a random variable

$u \quad$ Particular realisation of $U$

$H \quad$ Delay-time; time between a defect arising and the subsequent failure if left unattended; a random variable

$F_{H}(h)$ Cumulative distribution function (cdf) of $H$, independent of $U$

$h \quad$ Particular realisation of $H$

$\lambda \quad$ Defect arrival rate (intensity) per machine

\subsection{The maintenance model}

We consider two machines, each machine with a large number of identical bearings. The machines are identical and operating under steady-state conditions, so that it is reasonable to assume a complex-system delay-time model for each machine, with defects arising according to a Poisson process [28]. In this model, multiple concurrent defects are possible. We assume that the failure process follows the delay-time model. Thus, during a first stage (the time-to-defect arrival, $u$ ), a bearing is good and working normally. Then a defect arises, and in the second stage (the delaytime), the defective bearing deteriorates progressively and would fail $h$ time units later. If inspection is carried out during the second stage, the defect is revealed and the bearing is replaced with a new item from stock (more of this later).

The machines are inspected simultaneously every $T$ time units. We assume that the inspection process itself incurs no downtime. This is a reasonable assumption where inspection is outsourced to a condition monitoring specialist that provides periodic reports on bearing condition [52]. Defective bearings identified at inspection are replaced preventively, and the individual machine downtime is $d_{r}$ per bearing during this replacement. If there are multiple defects in the same machine then we assume that the preventive replacements take place consecutively. If there are 
multiple defects in the different machines, then preventive replacements also take place consecutively, M1 then M2, so that there is no simultaneous downtime of machines.

Failures are immediately revealed and operation of the machine ceases. A failed bearing is replaced immediately (provided a spare is available) to return the machine to operation. However, only failed bearings are replaced and the individual machine downtime is $d_{f}$ time units per bearing during this replacement. There is no inspection of bearings at failure events, unless inspection is scheduled. If an inspection is scheduled during failure replacement, then preventive replacement, if required, only commences once failure replacement is complete.

It is assumed that a machine is in a state of suspension during preventive and failure replacements. Therefore, defects grow, bearings age, and defects and failures arise only when a machine is operating. Any operational losses due to the presence of defects other than inspection, replacement and failure are ignored. These are standard assumptions in inspection models [27]. The model is depicted in Figure 1.

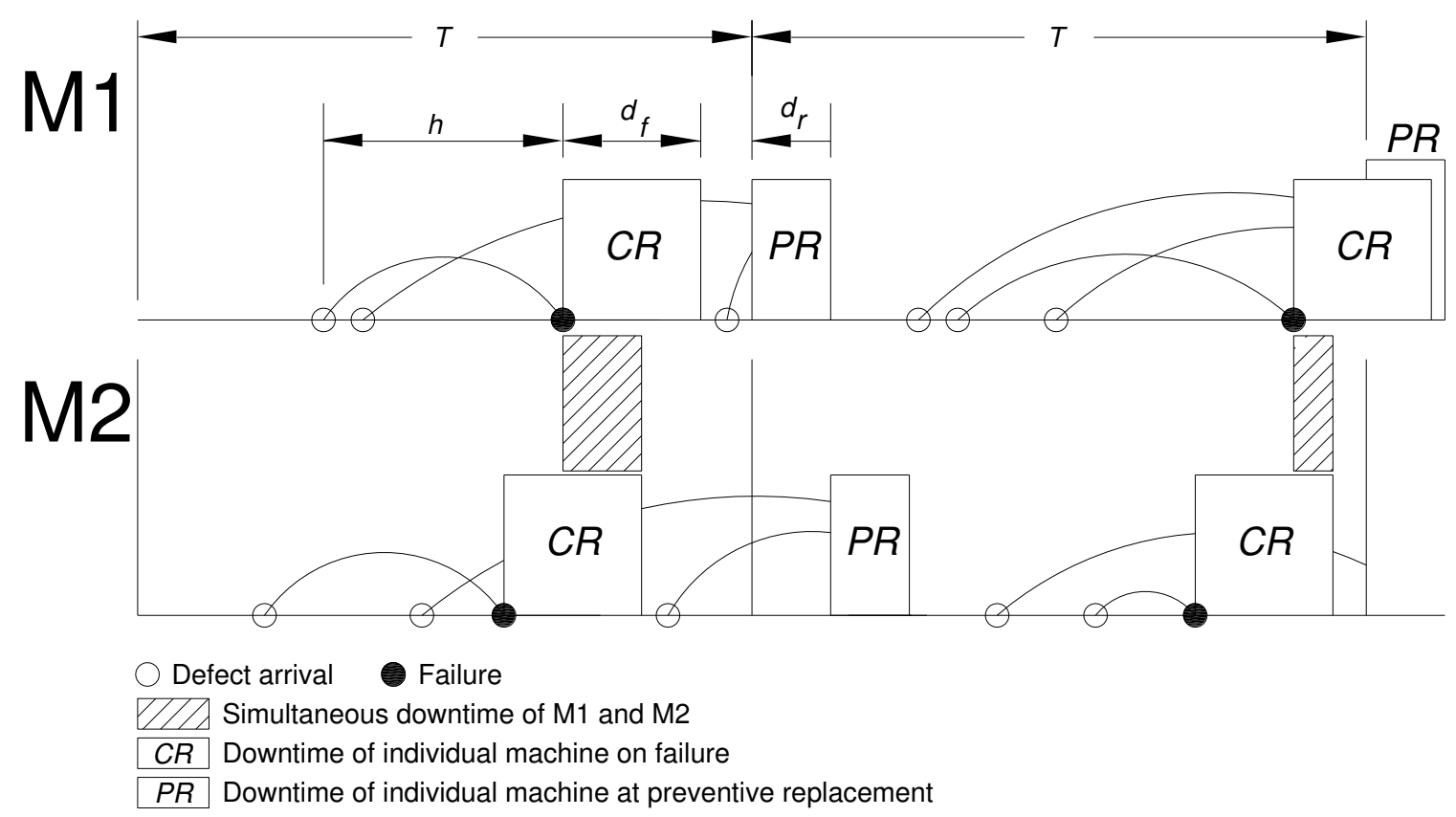

Figure 1. Two machines (M1 and M2) in parallel, subject to defect arrivals $\circ$, failures $\bullet$, periodic inspection interval $T$, downtime $d_{f}$ due to corrective replacement, CR, on failure, and downtime $d_{r}\left(d_{r}<d_{f}\right)$ due to preventive replacement, $\mathrm{PR}$, on defect found at inspection.

The complex-system delay-time model assumption means that we do not need to specify the number, $n$, of bearings in the system and the arrival rate per bearing separately. In a typical paperrolling machine, $n>100$ [27]. Based on the survey data (described in Section 2), we set $\lambda=0.125$ per machine per week, noting that without loss of generality we use one week as a convenient unit of time. This implies that there is one bearing defect arrival per machine every eight weeks and that for a machine with 100 bearings the mean bearing lifetime is 800 weeks, plus the mean delay-time. We suppose that the delay-time follows the Weibull distribution, $F_{H}(h)=1-\exp \left(-(h / \alpha)^{\beta}\right)$, with scale and shape parameters $\alpha=10$ and $\beta=3$, respectively, implying a mean delay-time of $\alpha \Gamma(1+1 / \beta)=8.93$ weeks [27]. The downtimes due to each replacement and failure are $d_{r}=4$ hours (survey range 1-6 hours) and $d_{f}=24$ hours (survey range 1-36 hours). The inspection cost $C_{i}$ is $£ 1,480$ (fixed cost of $£ 1,000$ for outsourced condition monitoring, plus one maintenance 
technician assisting the external specialists for an 8 hour shift). The individual machine downtime cost-rate $C_{d(\text { ind })}=£ 1,000$ per hour. The simultaneous machine downtime cost-rate $C_{d(\operatorname{sim})}=$ $£ 10,000$ per hour.

\subsection{The inventory control model}

We consider a single stock-keeping unit (SKU). This SKU is the bearing unit described in Section 2 and Section 3.2. We assume that the demand for this SKU is generated either by replacement of failed units or preventive replacement of defective units. Demand is satisfied from the existing inventory or by expediting an emergency order.

We consider the $(R, S)$ periodic review replenishment policy. Stock is reviewed every $R$ time units and an order is placed to bring the inventory position up to level $S$. If the inventory position at the review is $S$, then no order is placed and no order cost is incurred. The cost of stock review is assumed to be negligible. The lead-time for a normal order is $L_{o}$ and for an emergency order (at a stock-out) is $L_{s h}$. When order arrival and review of inventory coincide, the sequence of events is order-arrival then review.

Again based on the survey data, we set $C_{o}=£ 100$, including the cost of delivery. $C_{u}=£ 1,000$ per bearing (survey range $£ 1000-4000$ ). The holding cost, $C_{h}$, is costed at $1 \%$ of unit cost per week ( $£ 10$ per week). The emergency shipment cost, $C_{s h}$, is $£ 1,000$ (survey range $£ 500-1200$ ). The leadtime, $L_{o}$, is 4 weeks (survey range 2-6 weeks) and finally the shortage emergency delivery leadtime, $L_{s h}$, is 1 week (7 days) (survey range 1-10 days).

\subsection{The joint policy}

We denote the joint inventory and inspection policy by $(R, S, T)$, with $T=k R$ for some positive, rational number $k$. Two variants are considered. In the first, inspection and review of the inventory position sometimes coincide: this is the coincident $(R, S, T)$ policy. When they coincide, the sequence of events is inspect then review, so that the inventory position review takes account of items used for preventive replacement at the inspection. When $T=R(k=1)$ inspection and review always coincide. In the other variant, the inventory position is reviewed $L_{o}(<R)$ time units before the next inspection, so that stock, if ordered, arrives just in time for the next inspection: this is the just-in-time, JIT $(R, S, T)$ policy. When failures and inventory-review coincide, the sequence of events is failure then review.

The cost of a preventive replacement when a spare is available is $C_{r}=£ 4,720$. The components of this cost are the machine downtime cost $\left(d_{r} \times C_{d(\text { ind })}\right)$ and the cost of three maintenance technicians $\left(3 \times d_{r} \times C_{m}\right)$. When a spare is not available and an emergency order must be placed, the additional cost of the emergency order $C_{s h}$ and the downtime cost during the lead-time $L_{s h} \times C_{d(\text { ind })}$ are incurred, so that $C_{r}=£ 173,720$. The cost of a failure replacement when a spare is available is $C_{f}=£ 28,320$. When a spare is not available $C_{f}=£ 197,320$. These costs share the cost-component of $C_{r}$ with the addition of $£ 23,600$ for the machine downtime of length $d_{f}$. These costs are based on the survey data.

If failure replacement has to wait for the other machine to come up, because the other machine is subject to preventive replacement or failure replacement, then simultaneous downtime cost is incurred. Preventive replacement cost is not affected in this way because a preventive replacement waits until a failure replacement is complete. Note, it is this kind of complexity that makes a closed form expression for the cost rate very difficult or impossible to obtain. 


\section{The simulation model}

The simulation model was developed using ProModel, a process-based discrete-event simulation package [53]. The basic framework in the modular approach of ProModel requires the use of at least four modules: Locations; Entities; Arrivals; and Processing (LEAP). Variables, attributes, subroutines, resources and path networks were used extensively for further developing the programming code. Macros were set up to enable the easy alteration of decision variables. So that our results may be reproduced [54], flow-charts for the simulation are provided: Appendix 1, procedure for the JIT $(R, S, T=R)$ policy, and Appendices 2-4, planned downtime. Figures 2 and 3 also illustrate flow charts for cost-rate calculation and the identification of simultaneous machine downtime, respectively. These flow charts demonstrate how cost-rates are calculated, and how the cost-optimal policy is determined.

The simulation is non-terminating so that the run-length must be specified. Also, as we wish to investigate the system only during steady-state, we must specify a warm-up period, during which cost and downtime outputs are not used in the calculation of the decision criterion. For the simulation, we use the Time Series method based on the weekly cost mean value and Welch's method based on the weekly cost moving average [55] with a window length of 5 to determine the warm-up period for the model. This justifies a conservative warm-up of 1,000 weeks. Common simulation practice uses a warm-up and a long run-length for non-terminating simulations. It is recommend that the run-length is at least 10 times the warm-up [56,57]. However, since simultaneous machine downtime occurrences are rare in our model, we used a much longer runlength of 500,000 weeks. The simulation programme was efficient and the computation time took 5 minutes on a standard desktop PC. Outputs from the simulation enabled us to report the values of quantities that are discussed in the results, next. Optimisation was performed using SimRunner [58]. This tool uses a meta-heuristic search method [59], whose primary algorithm is the genetic algorithm, to optimise the decision variables. 


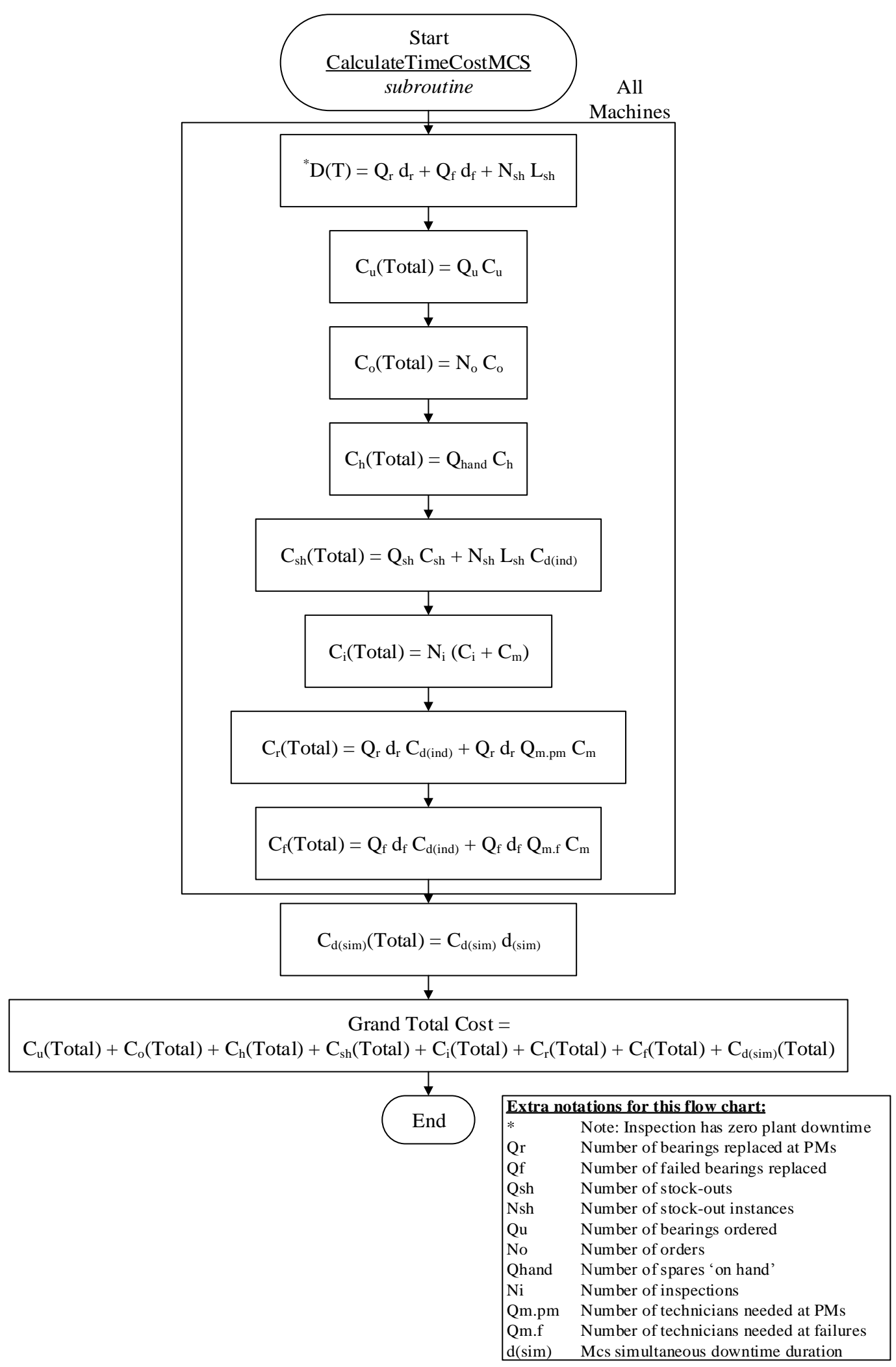

Figure 2. Flowchart of the "Calculate Time \& Cost" subroutine (multi-line). 


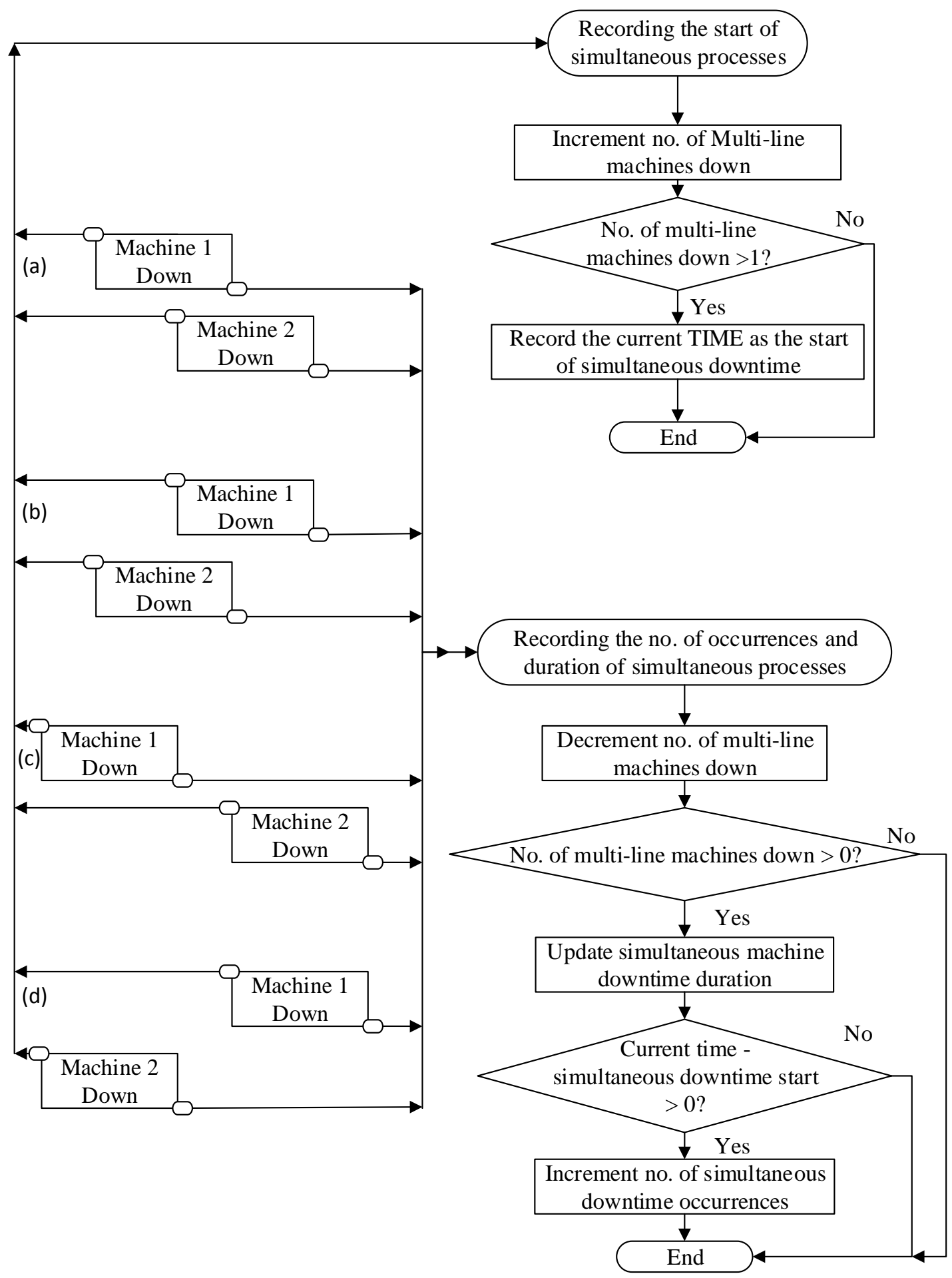

Figure 3. Flowchart, depicting the process of capturing and recording simultaneous machine downtime. 


\section{Results}

Two joint inventory-inspection policy variants were studied in the context of the paper mill with two parallel machines: $(R, S, T=k R)$, with coincident and just-in-time ordering, and for $k=$ $0.5,1,2,3,4$. Figure 4 illustrates a subset of these policies. For each variant and a given $k$, there are three decision variables (with two degrees of freedom): the review period $R$; the inspection interval $T$ (implied by $k$ ); and the order-up-to level, $S$. We sought those values of the decision variables that minimise the long-run total cost per unit time, or cost-rate, $C_{\infty}$.

a)

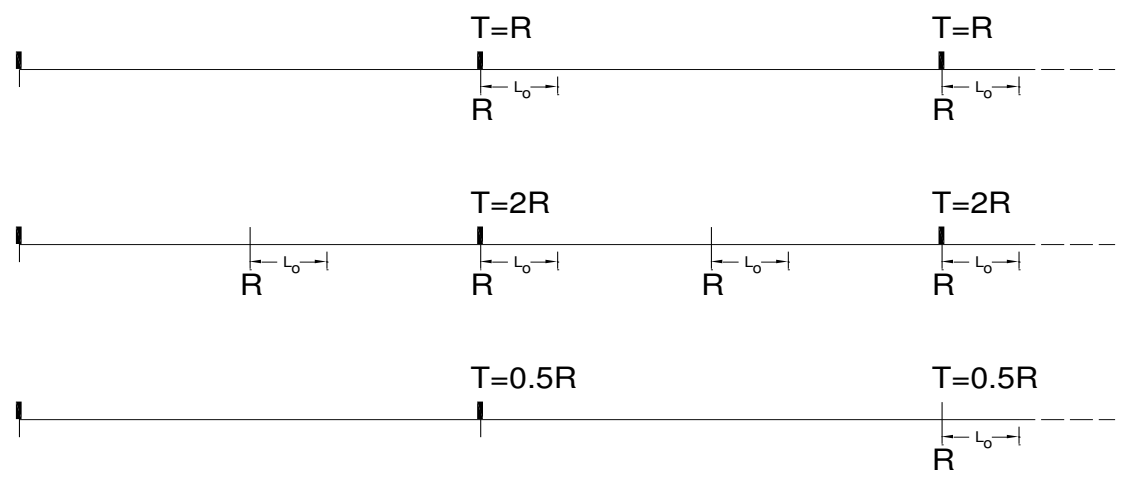

b)
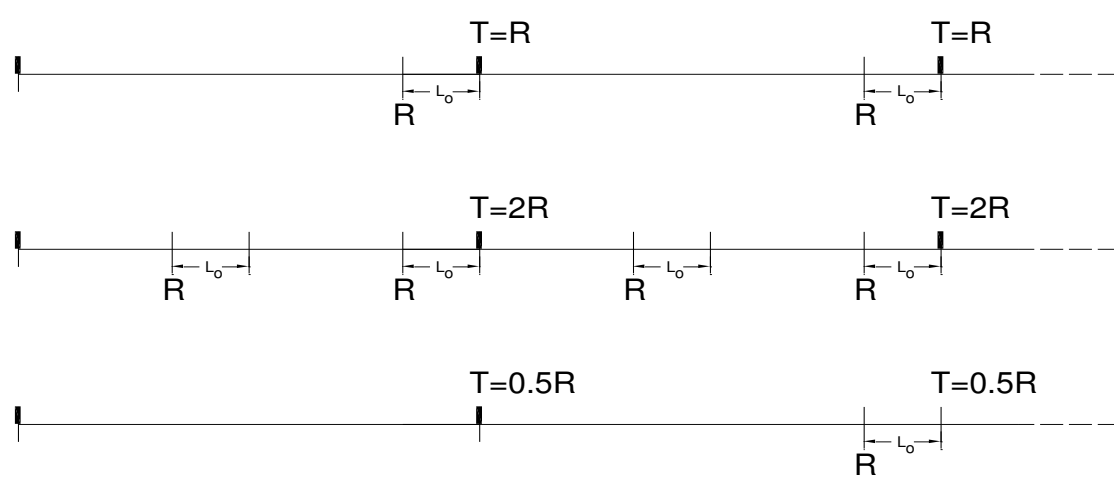

Figure 4. Policies with: a) coincident; and b) just-in-time ordering for $k=1$ (top), $k=2$ (middle), and $k=0.5$ (bottom).

Table 1 shows the results for the best (lowest cost) policy variants. The results show that the $(R, S, T=R)$ policy using just-in-time ordering with $T^{*}=5, S^{*}=6$ has the lowest cost-rate (Figure 5a), inspecting bearings every 5 weeks, reviewing stock at the same frequency and ordering sufficient spares to return the inventory position to 6 units (Figure $5 \mathrm{~b}$ ). The second lowest cost-rate policy, $(R, S, T=0.5 R)$, also uses just-in-time ordering, inspecting every 5 weeks but reviewing stock every 10 weeks. The third best policy, $(R, S, T=R)$, uses the same frequency of inspection and stock-review as the cost-optimal policy but using coincident ordering. Other values of $k$ were investigated but had higher cost-rates: 2289.0; 2302.4; and 2319.1 using just-in-time ordering, and 2290.9; 2303.8; and 2319.1 using coincident ordering, for $k=2,3,4$, respectively. The results generally suggest that it is not cost-optimal to carry out multiple stock-reviews between inspections. This is because demands for spares between inspections do not occur sufficiently often, since failures are rare, to justify the additional cost of order placements. 
Table 1. Cost-rate comparison (cost-optimal policy in bold).

\begin{tabular}{|c|c|c|c|c|c|c|c|c|}
\hline \multirow[b]{3}{*}{ T/weeks } & \multicolumn{4}{|c|}{ Cost-rate } & \multicolumn{4}{|c|}{$\%$ increase relative to optimum } \\
\hline & \multicolumn{2}{|c|}{ Just-in-time } & \multicolumn{2}{|c|}{ Coincident } & \multicolumn{2}{|c|}{ Just-in-time } & \multicolumn{2}{|c|}{ Coincident } \\
\hline & $T=R$ & $T=0.5 R$ & $T=R$ & $T=0.5 R$ & $T=R$ & $T=0.5 R$ & $T=R$ & $T=0.5 R$ \\
\hline 2 & 3009.4 & 3003.7 & 3011.8 & 3003.7 & 33.0 & 32.7 & 33.1 & 32.7 \\
\hline 3 & 2548.7 & 2533.5 & 2548.7 & 2545.5 & 12.6 & 11.9 & 12.6 & 12.5 \\
\hline 4 & 2329.1 & 2349.6 & 2344.5 & 2348.6 & 2.9 & 3.8 & 3.6 & 3.8 \\
\hline 5 & 2263.4 & 2267.6 & 2281.3 & 2288.7 & 0.0 & 0.2 & 0.8 & 1.1 \\
\hline 6 & 2284.7 & 2292.5 & 2304.5 & 2310.4 & 0.9 & 1.3 & 1.8 & 2.1 \\
\hline 7 & 2391.1 & 2422.1 & 2422.4 & 2425.9 & 5.6 & 7.0 & 7.0 & 7.2 \\
\hline 8 & 2541.6 & 2569.0 & 2554.0 & 2556.4 & 12.3 & 13.5 & 12.8 & 12.9 \\
\hline 9 & 2701.6 & 2721.7 & 2713.6 & 2746.0 & 19.4 & 20.3 & 19.9 & 21.3 \\
\hline 10 & 2896.6 & 2931.0 & 2948.6 & 2975.6 & 28.0 & 29.5 & 30.3 & 31.5 \\
\hline
\end{tabular}
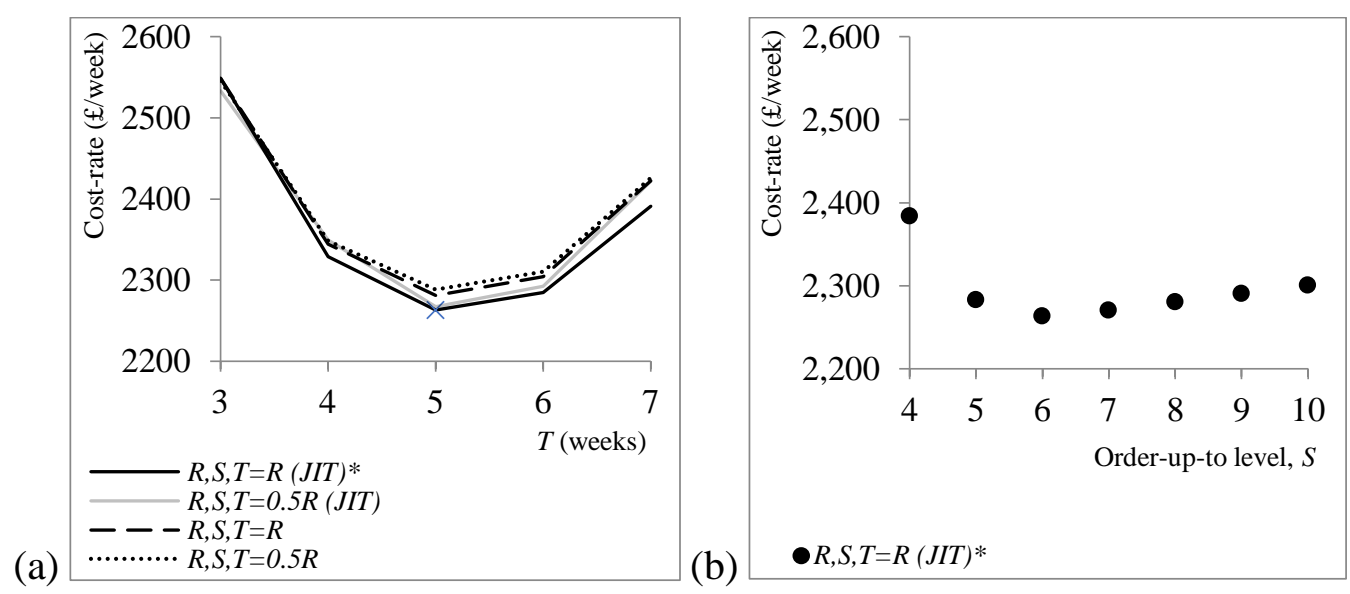

Figure 5. Cost-rate versus (a) inspection interval (optimal policy ${ }^{*}$; optimum interval ${ }^{\mathrm{X}}$ ); (b) order-up-to level $S$ for the cost-optimal policy with $T$ at optimal value (5 weeks).

The right-hand columns of Table 1 show the percentage difference in cost of the relevant policies compared to the cost-optimal policy. It is interesting to observe that, moving the inspection interval $T$ by 1 week to either side of the optimum has bigger cost effect $(+2.9 \%$ and $+0.9 \%$ for $T=4$ and $T=6$, respectively) than changing the type of policy $(+0.2 \%$ for $J I T \mathrm{k}=0.5$, and $+0.8 \%$ for coincident $\mathrm{k}=1$ ), suggesting that maintenance planning should be prioritised over inventory planning.

Under the cost-optimal policy, potentially more frequent reviews are undertaken (every 5 weeks) compared to the second best policy, which will review stock every 10 weeks, thus reducing stock-outs and ultimately reducing cost. Thus, to reduce the possibility of stock-outs, more reviews might be undertaken, for $(R, S, T=R)$, or more stock might be held, for $(R, S, T=0.5 R)$, depending on the relative sizes of the order cost and the holding cost. Clearly, the cost of inventory holding is traded-off with the cost of stock-outs, which lies at the heart of inventory decision making.

Comparing the ordering cost-rate for the best four policies, Figure 6a demonstrates that the costs for the $(T=R)$ policies are higher $(55 \%$ higher at the optimum interval) since these can potentially undertake more reviews. Thus comparing Figures $6 \mathrm{a}$ and $6 \mathrm{~b}$, it can be seen that for each policy type (just-in-time and coincident ordering) where the ordering cost-rate is high, the holding cost-rate is low, and vice versa. The holding cost-rate is mainly influenced by the frequency of review and the order-up-to level $S$, and appears to have a significant effect on the policy ranking. 
Clearly, the timely review of the stock, ordering to the optimal level $S^{*}$, will result in keeping less stock and a lower holding cost-rate. Whereas the difference between the overall cost-rates of the best and the second best policies is only $£ 4.25$ (0.2\%) (Table 1), the difference between the holding cost-rates for the same policies is $£ 3.90$ (Figure 6b), which accounts for $92 \%$ of the cost difference. This implies that the holding cost-rate has a significant effect on the choice of policy.

(a)

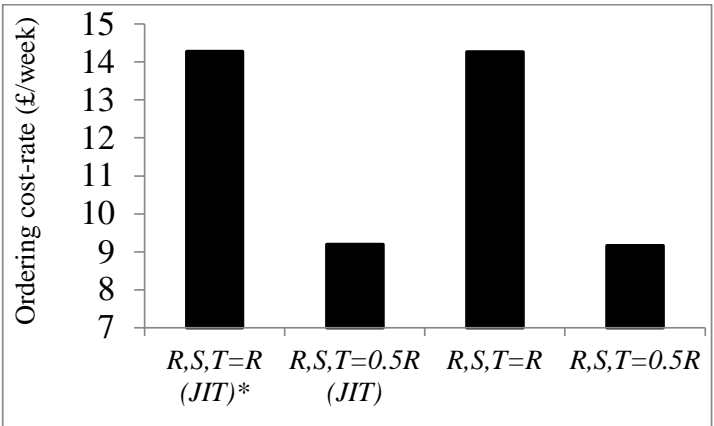

(c)

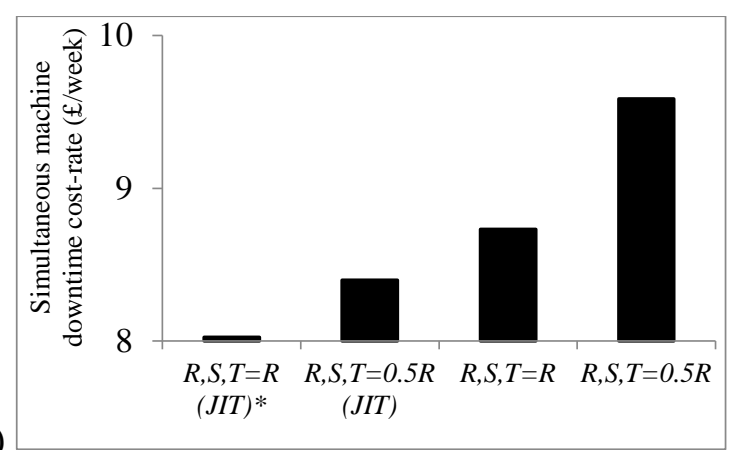

(b)
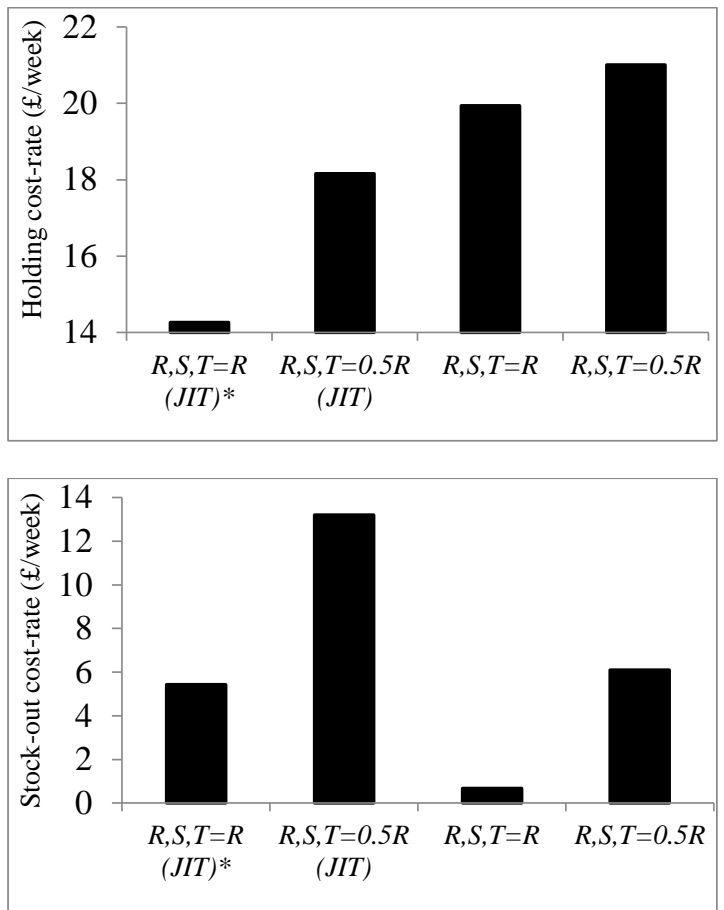

Figure 6. For the best four joint policy variants at optimum interval (*optimum policy): (a) ordering costrate; (b) holding cost-rate; (c) simultaneous machine downtime cost-rate; and (d) stock-out cost-rate.

Although the simultaneous machine downtime cost does not seem to be a significant contributor to cost-rate, Figure $6 \mathrm{c}$ shows that it aligns with the policy ranking, so that the best policy has the lowest simultaneous downtime cost and the worst policy (of the four) the highest simultaneous downtime cost. It is interesting to note that both holding cost-rate (Figure 6b) and simultaneous machine downtime cost-rate (Figure $6 \mathrm{c}$ ) display a similar pattern. The implication is that the two policies that review spares less frequently $(T=0.5 R$ policies $)$ and the policy that has its spares delivered out-of-sequence with inspection ( $T=R$ policy using coincident ordering) are likely to have higher simultaneous machine downtime cost due to higher chance of a stock-out. This observation certainly appears to be evident in Figure 6c.

A number of points should be noted about the stock-out cost-rate shown in Figure 6d. First, as expected, for the $(T=0.5 R)$ policies, the cost-rates are much higher since the frequency of review is half that of inspection, and stock-outs are therefore more likely. Second, the variation across the policies is relatively large, considering the overall cost-rate differences between policies. The third point is that generally the stock-out cost-rates are much lower than the failure cost-rates shown in Table 2 (row 10). Fourth, the $(R, S, T=R)$ policy using coincident ordering, which may be perceived as a low risk policy since it has the lowest stock-out cost-rate, has a large ordering costrate (Figure 6a). The fifth point is that the optimal policy has the second lowest stock-out cost-rate, which is much lower than the inferior policy (59\% lower), making it a relatively low-risk policy. Finally, in general, stock-out cost-rates (Figure 6d) and ordering cost-rates (Figure 6a) display 
opposite trends: policies which have low ordering cost-rates tend to have high stock-out cost-rates, and vice versa.

In summary, it is inspection frequency and then just-in-time ordering that have the greatest influences on the policy ranking. In addition, component cost-rates, including the holding cost-rate, the simultaneous machine downtime cost-rate, and the stock-out cost-rate, are traded-off. These also have an influence on the policy ranking. Thus, the different policies, at their optimal settings, place different demands on inventory.

\subsection{Analysis of the cost-optimal policy}

The results for the cost-optimal " $(R, S, T=R)-J I T$ " policy were further analysed in detail and are shown in Table 2.

Table 2. The detailed analysis of the cost-optimal policy ("

\begin{tabular}{|c|c|c|c|c|c|c|c|}
\hline & \multirow[b]{2}{*}{ Description } & \multicolumn{6}{|c|}{ Inspection interval, $T$ (weeks) } \\
\hline & & 3 & 4 & 5 & 6 & 7 & 8 \\
\hline 1 & Defect removal rate ${ }^{* \#}$ & 24.8 & 24.6 & 24.3 & 23.8 & 23.1 & 22.3 \\
\hline 2 & Failure rate ${ }^{* \#}$ & 0.2 & 0.4 & 0.7 & 1.2 & 1.8 & 2.6 \\
\hline 3 & Arrival rate ${ }^{* \#}$ & 25.0 & 25.0 & 25.0 & 25.0 & 25.0 & 25.0 \\
\hline 4 & Positive inspection rate ${ }^{* \#}$ & 20.7 & 19.4 & 18.2 & 17.0 & 15.8 & 14.8 \\
\hline 5 & Inspection rate ${ }^{* \#}$ & 66.7 & 50.0 & 40.0 & 33.3 & 28.6 & 25.0 \\
\hline 6 & Percentage positive inspections & 31 & 39 & 46 & 51 & 55 & 59 \\
\hline 7 & Spares used at PMs ${ }^{* \#}$ & 24.8 & 24.6 & 24.3 & 23.8 & 23.1 & 22.3 \\
\hline 8 & Spares ordered ${ }^{\#}$ & 25.0 & 25.0 & 25.0 & 25.0 & 25.0 & 25.0 \\
\hline 9 & Stock review rate ${ }^{\#}$ & 33.3 & 25.0 & 20.0 & 16.7 & 14.3 & 12.5 \\
\hline 10 & Mean order size & 1.0 & 1.6 & 1.8 & 1.9 & 2.1 & 2.3 \\
\hline 11 & Preventive replacement cost-rate & 1171.4 & 1160.8 & 1145.0 & 1121.9 & 1090.9 & 1054.0 \\
\hline 12 & Inspection cost-rate & 986.7 & 740.0 & 592.0 & 493.3 & 422.9 & 370.0 \\
\hline 13 & Failure replacement cost-rate & 43.7 & 105.8 & 198.9 & 335.4 & 519.6 & 737.5 \\
\hline 14 & Ordering cost-rate & 25.8 & 15.8 & 14.3 & 13.0 & 11.8 & 10.8 \\
\hline 15 & Holding cost-rate & 20.0 & 20.0 & 20.0 & 20.0 & 20.0 & 20.0 \\
\hline
\end{tabular}

In particular, we see that the number of defects identified and thus removed declines as inspection becomes less frequent (row 1) and the failure-rate increases in return (row 2), since these must sum to 25 (row 3), the assumed defect arrival rate (noting that an intensity of 0.125 defects per machine per week implies 25 defects in total per 100 weeks). Less frequent inspection also implies inspections are positive (at least one defect found) more often. This is demonstrated in row 6, which shows the ratio of positive inspection rate (row 4) to inspection rate (row 5). Both the number of spares required at inspections (row 7) and the number of spares ordered (row 8) correspond exactly to the defect removal rate and the defect arrival rate, as required by the model. Also on the inventory side, the stock-review rate is the inverse of the inspection frequency (row 9), and as stock-review becomes less frequent, the mean order size (row 10) increases in response, but the holding cost-rate (row 13) remains fixed.

Rows 11 to 15 display variations in five cost-rates, and overall these show that maintenance costs dominate inventory costs. Individually, the costs all vary with the inspection interval (except the holding cost-rate for the inspection intervals shown) in a way that is expected. 
The sensitivity of the optimal policy to parameter variation was investigated. Figure 7 shows this sensitivity with respect to six parameters, in the order of the strength of the sensitivity, greatest to smallest. For other parameters $\left(C_{h}, C_{d(\operatorname{sim})}, C_{o}, L_{s h}\right.$, and $\left.C_{s h}\right)$, there was less sensitivity.
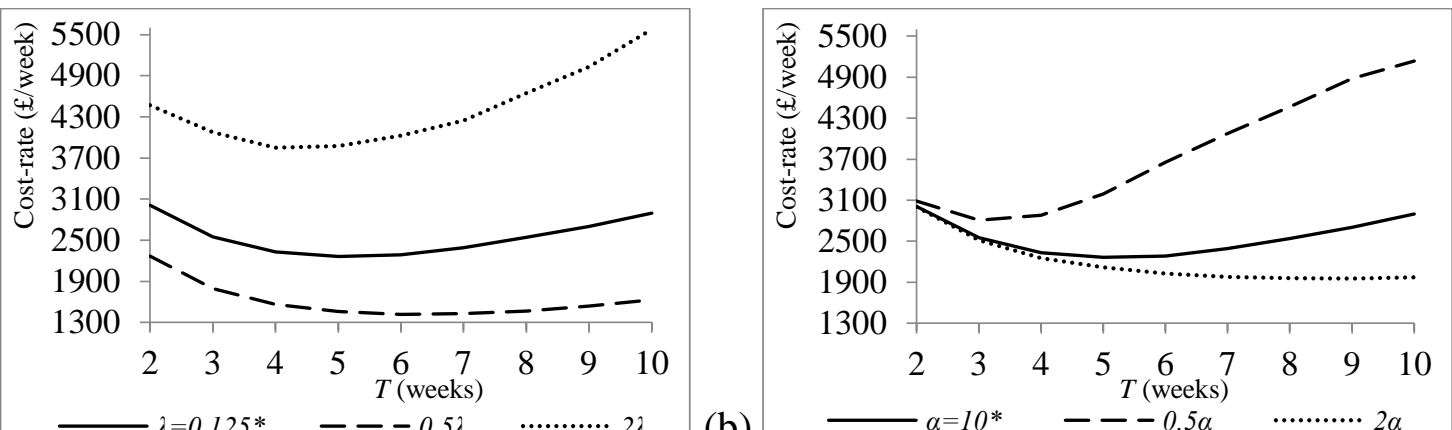

(a)

(b)
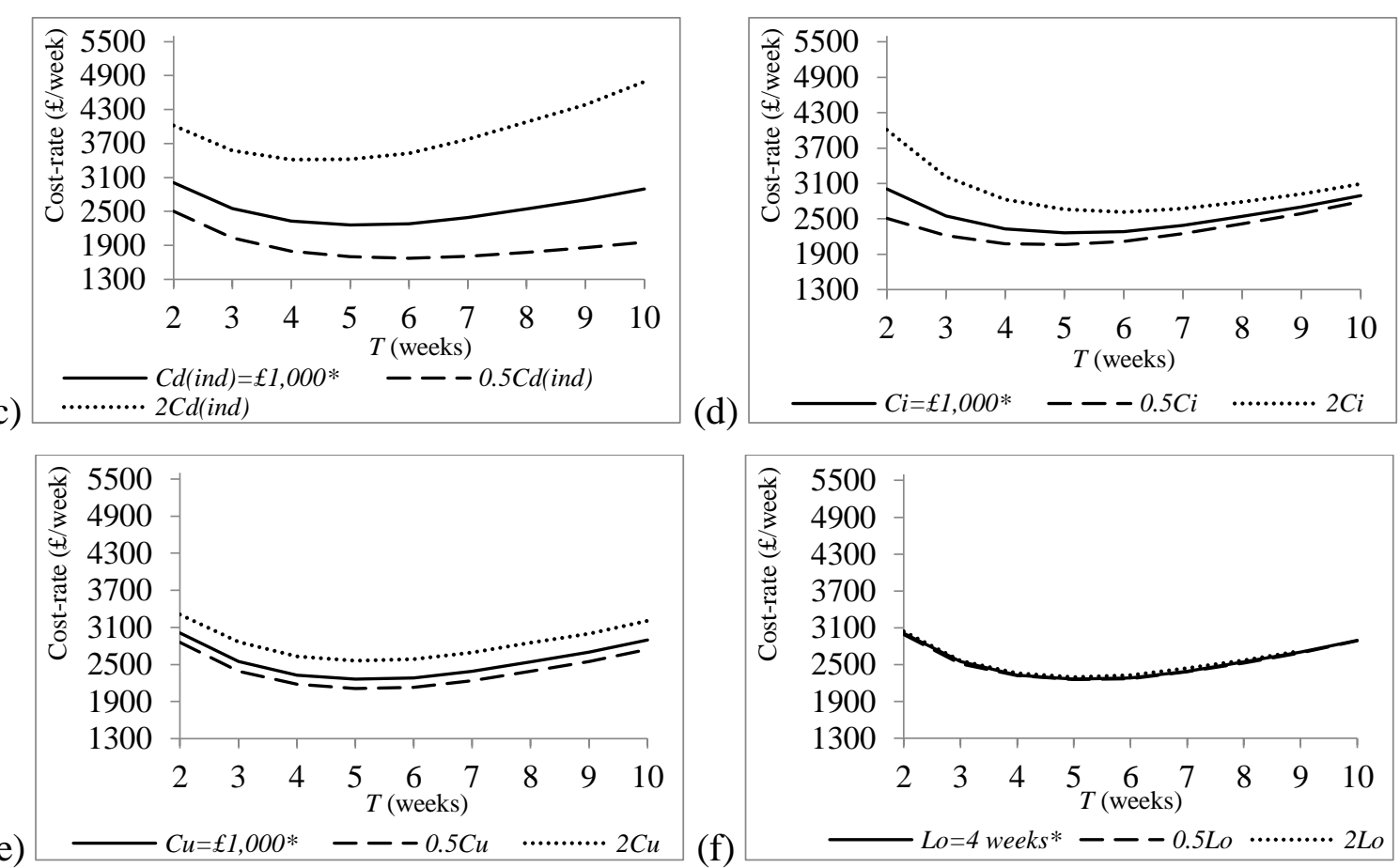

(d)

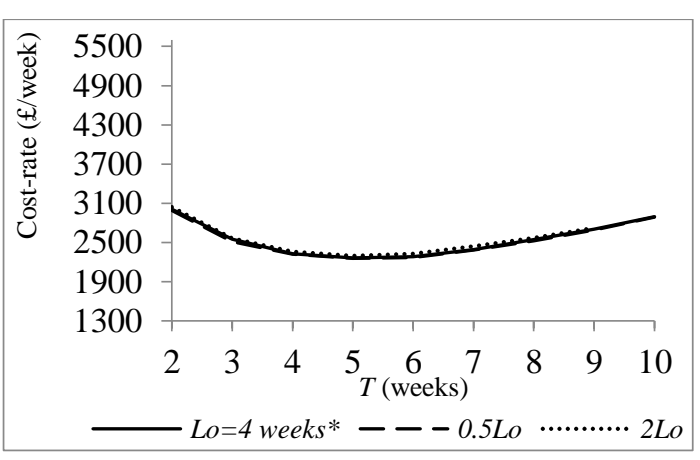

Figure 7. Sensitivity of the cost-optimal policy ("baseline) to: (a) defect arrival rate; (b) failure delay-time;

(c) individual machine downtime cost-rate; (d) inspection cost; (e) unit cost; and (f) lead-time.

The policy is most sensitive to the defect arrival intensity (Figure 7a), since this drives the maintenance costs and these costs dominate the inventory costs. The scale parameter, $\alpha$, of the Weibull delay-time distribution is next most important (Figure 7b), as this determines the balance between failures and defects found at inspection, the latter being less costly overall. As $\alpha$ increases, inspection can be relaxed (less frequent) and the overall cost-rate reduces. The direction of sensitivity to the downtime cost-rate (Figure 7c) and to the unit cost of inspection (Figure 7d) is as expected. More frequent inspection is the response to higher cost of downtime. The opposite effect occurs with the cost of inspection. The unit cost of spares (Figure 7e) and the lead-time (Figure 7f) have a small effect on the policy. For the latter, this is expected because the optimal policy uses just-in-time ordering. Changing the values of the other parameters has little effect on the costoptimal policy (results omitted for brevity). In particular, the effects of $L_{s h}$ and $C_{s h}$ are small because shortages are rare when maintenance and inventory are jointly optimised. The same applies 
for the simultaneous machine downtime cost-rate parameter because simultaneous machine downtime is rare.

\section{Conclusions}

Several simulation models were developed to study the maintenance and spare parts inventory of a parallel production facility. The aim was to jointly optimise the planned maintenance inspection interval, $T$, and the review period, $R$, and the order-up-to level, $S$, of the periodic review inventory replenishment policy. A paper mill with two parallel machines provided the industrial context, and simulation models were specifically developed for this system, focusing on a single stock keeping unit (bearings). Since simulation is not an optimisation technique, SimRunner (an optimisation tool) was integrated with ProModel simulation package to find the optimal policy. Although the models are developed in the context of a parallel production facility in a paper mill making plant, using survey data related to that, the models are scalable to other multi-line industrial situations, provided model parameters can be specified.

This is the first joint maintenance and inventory optimisation study that addresses a parallel system. The possibility of simultaneous downtime of the parallel machines characterises the dependence between the machines in our model. We suppose that simultaneous machine downtime stops production completely and incurs significant cost to the system operator.

The optimal policy is such that inspection and stock review occur at the same frequency and orders are placed so that stock arrives immediately before inspection. This is the $(R, S, T=R)$-justin-time policy. It has the lowest holding and simultaneous machine downtime cost-rates, and a relatively low stock-out cost-rate, among the policy variations we study. Ordering in advance of inspection thus reduces holding costs because less stock is held on average, relative to the policy which orders stock immediately following inspection. This latter policy is the $(R, S, T=R)$ coincident policy, noting that in the coincident policy the order of events is first inspect and then review stock. It is also not cost-effective to place multiple orders between inspections. Where the ordering cost-rate is high, the holding cost-rate is low, and vice-versa. While the cost-rates are very similar across the four lowest cost policies, the components of the cost-rates are quite diverse because the trade-offs are different, and so the different policies place different demands on inventory.

The defect arrival rate and the cost of emergency shipment parameters have the most and least impact on the cost-optimal policy, respectively. The effect of different values of parameters on the cost-optimal policy give results that are broadly expected. When sensitivity analysis is broadly in line with expectations, it partly validates the simulation results, but at the same time increases the confidence for relying on results which are less obvious.

These particular results relate to the context that determines the parameter values. However, in other contexts other particular conclusions may follow from specific simulation models developed for those contexts. Thus, the point of the paper is to model jointly maintenance and inventory planning rather than to determine whether a just-in-time policy is better or worse than a coincident policy. Further, since failure times are random and the number of spares needed at inspection is random, a known number of spares (one) is required at unknown times and an unknown number of spares is required at known times (at inspections). Thus, without modelling, it will not be clear in a given context when inspections should be performed and when spares should be ordered and in what quantity. This, and the suggestion that maintenance planning should take priority over 
inventory planning, are the main implications of this work for the paper mill case that motivates this study.

Extensions to the work presented in this paper may be developed in several directions. The simulation models may be developed further by relaxing the assumption of "perfect inspection", which is rare in industrial situations. Models using variable replenishment lead-time may be developed since in practice it is unlikely to know the exact duration of lead-time in advance. Manpower planning will also be essential if models are to be implemented in practice, provided the data are based on real industrial situations. With the flexibility of simulation, there is no reason why these additional logistical factors cannot be considered to make the model even closer to reality. The joint optimisation for dependent and/or non-identical units in parallel systems might also be considered. Finally, joint modelling of inspection and an inventory policy that uses historic data and dynamic demand forecasting would be an interesting study.

\section{References}

[1] Alsyouf I, Shamsuzzaman M, Abdelrahman G, Al-Taha M. Improving reliability of repairable systems using preventive maintenance and time-between-failures monitoring. European Journal of Industrial Engineering 2016; 10: 596-617.

[2] Ding SH, Kamaruddin S. Maintenance policy optimization - literature review and directions." International Journal of Advanced Manufacturing Technology 2015; 76: 1263-283.

[3] Wall D. Trunnion bearing replacement on a BOS Plant. Maintenance \& Engineering: MaintenanceOnLine.Co.UK 2013; March: 22.

[4] Sharma A, Yadava GS. A literature review and future perspectives on maintenance optimization. Journal of Quality in Maintenance Engineering 2011; 17: 5-25.

[5] Panagiotidou S. Joint optimization of spare parts ordering and maintenance policies for multiple identical items subject to silent failures. European Journal of Operational Research 2014; 235: 300-314.

[6] Ruschel E, Portela Santos EA, De Freitas Rocha Loures E. Industrial maintenance decision-making: a systematic literature review. Journal of Manufacturing Systems 2017; 45: 180-194.

[7] Zahedi-Hosseini F, Syntetos AA, Scarf PA. Optimisation of inspection policy for multi-line production systems. European Journal of Industrial Engineering. In Press. 2017.

[8] Van Horenbeek A, Buré J, Cattrysse D, Pintelon L, Van Steenwegen P. Joint maintenance and inventory optimization systems: A review. International Journal of Production Economics 2013; 143: 499-508.

[9] Scarf PA. On the application of mathematical models in maintenance. European Journal of Operational Research 1997; 99: 493-506.

[10] Alrabghi A, Tiwari A, Savill M. Simulation-based optimisation of maintenance systems: Industrial case studies. Journal of Manufacturing Systems 2017; 44: 191-206.

[11] Sarker BR, Faiz TI. Minimizing maintenance cost for offshore wind turbines following multi-level opportunistic preventive strategy. Renewable Energy 2016; 85: 104-113.

[12] Irawan CA, Ouelhadj D, Jones D, Stålhane M, Sperstad, IB. Optimisation of maintenance routing and scheduling for offshore wind farms. European Journal of Operational Research 2017; 256: 76-89.

[13] Wang HZ. A survey of maintenance policies of deteriorating systems. European Journal of Operational Research 2002; 139: 469-489.

[14] Alaswad S, Xiang Y. A review on condition-based maintenance optimisation models for stochastically deteriorating system. Reliability Engineering and System Safety 2017; 157: 54-63.

[15] Olde Keizer MCA, Flapper SDP, Teunter RH. Condition-based maintenance policies for systems with multiple dependent components: A review. European Journal of Operational Research 2017; 261: 405420. 
[16] Scarf PA, Cavalcante CAV. Modelling quality in replacement and inspection maintenance. International Journal of Production Economics 2012; 135: 372-381.

[17] Christer AH. Developments in delay time analysis for modelling plant maintenance. Journal of the Operational Research Society 1999; 50; 1120-1137.

[18] Wang W. An overview of the recent advances in delay-time-based maintenance modelling. Reliability Engineering and System Safety 2012; 106: 165-178.

[19] Pandey MD, Cheng T, Van der Weide JAM. Higher moments and probability distribution of maintenance cost in the delay time model. Journal of Risk and Reliability 2016; 230: 354-363.

[20] Yang L, Ma X, Zhai Q, Zhao Y. A delay time model for a mission-based system subject to periodic and random inspection and postponed replacement. Reliability Engineering and System Safety 2016; 150: 96-104.

[21] Berrade MD, Scarf PA, Cavalcante CAV. A study of postponed replacement in a delay time model. Reliability Engineering and System Safety 2017; 168: 70-79.

[22] Jiang R. An efficient quasi-periodic inspection scheme for a one-component system. IMA Journal of Management Mathematics 2017; 28: 373-386.

[23] Emovon I, Norman RA, Murphy AJ. An integration of multi-criteria decision making techniques with a delay time model for determination of inspection intervals for marine machinery systems." Applied Ocean Research 2016; 59: 65-82.

[24] Silver EA, Pyke DF, Thomas DJ. Inventory Management and Production Planning and Scheduling. Third Edition. Wiley, New York, 2016.

[25] Zahedi-Hosseini F, Scarf PA, Syntetos AA. Joint optimisation of inspection maintenance and spare parts provisioning: a comparative study of inventory policies using simulation and survey data. Reliability Engineering and System Safety 2017; 168: 306-316.

[26] Nicolai RP, Dekker R. Optimal maintenance of multi-component systems: A review. In Complex System Maintenance Handbook (Murthy, Kobbacy Eds), Springer, London, 2008; 263-286.

[27] Wang W. A joint spare part and maintenance inspection optimisation model using the delay-time concept. Reliability Engineering and System Safety 2011; 96: 1535-1541.

[28] Wang W. A stochastic model for joint spare parts inventory and planned maintenance optimisation. European Journal of Operational Research 2012; 216: 127-139.

[29] Vaughan TS. Failure replacement and preventive maintenance spare parts ordering policy. European Journal of Operations Research 2005; 161: 183-190.

[30] Boschian V, Rezg N, Chelbi A. Contribution of simulation to the optimization of maintenance strategies for a randomly failing production system. European Journal of Operational Research 2009; 197: 11421149.

[31] De Smidt-Destombes KS, Van Der Heijden MC, Van Harten A. Joint optimisation of spare part inventory, maintenance frequency and repair capacity for k-out-of-N systems. International Journal of Production Economics 2009; 118: 260-268.

[32] Gan S, Zhang Z, Zhou Y, Shi J. Joint optimization of maintenance, buffer, and spare parts for a production system. Applied Mathematical Modelling 2015; 39: 6032-6042.

[33] Sarker R, Haque A. Optimization of maintenance and spare provisioning policy using simulation. Applied Mathematical Modelling 2000; 24: 751-760.

[34] Chelbi A, Ait-Kadi D. Spare provisioning strategy for preventively replaced systems subjected to random failure." International Journal of Production Economics 2001; 74: 183-189.

[35] Yoo YK, Kim KJ, Seo J. Optimal joint spare stocking and block replacement policy (cost modelling of spare stocking and block replacement). International Journal of Advanced Manufacturing Technology 2001; 18: 906-909

[36] Brezavscek A, Hudoklin A. Joint optimization of block replacement and periodic-review spareprovisioning policy. IEEE Transactions on Reliability 2003; 52: 112-117. 
[37] Ilgin MA, Tunali S. Joint optimization of spare parts inventory and maintenance policies using genetic algorithms. International Journal of Advanced Manufacturing Technology 2007; 34: 594-604.

[38] Huang R, Meng L, Xi L, Liu C. Modeling and analyzing a joint optimization policy of blockreplacement and spare inventory with random-leadtime. IEEE Transactions Reliability 2008; 57: 113124.

[39] Samal NK, Pratihar DK. Joint optimization of preventive maintenance and spare parts inventory using genetic algorithms and particle swarm optimization algorithm. International Journal of System Assurance Engineering and Management 2015; 6: 248-258.

[40] Jiang Y, Chen M, Zhou D. Joint optimization of preventive maintenance and inventory policies for multi-unit systems subject to deteriorating spare part inventory. Journal of Manufacturing Systems 2015; 35: 191-205.

[41] Chen L, Ye ZS, Xie M. Joint maintenance and spare parts provisioning policy for k-out-of-n systems. Asia-Pacific Journal of Operational Research 2013; 30: 1-21.

[42] Zhang X, Zeng J. Joint optimisation of condition-based opportunistic maintenance and spare parts provisioning policy in multiunit systems. European Journal of Operational Research 2017; 262: 479498.

[43] Olde Keizer MCA, Teunter RH, Veldman J. Joint condition-based maintenance and inventory optimisation for systems with multiple components. European Journal of Operational Research 2017; 257: 209-222.

[44] Alrabghi A, Tiwari A. A novel approach for modelling complex maintenance systems using discrete event simulation. Reliability Engineering and System Safety 2016; 154: 160-170.

[45] Zahedi-Hosseini F. Modelling and simulation for the joint optimisation of inspection maintenance and spare parts inventory in multi-line production settings. PhD Thesis. University of Salford, 2017.

[46] Cai J, Yin Y, Zhang L, Chen X. Joint Optimization of Preventive Maintenance and Spare Parts Inventory with Appointment Policy. Mathematical Problems in Engineering 2017; https://doi.org/10.1155/2017/3493687.

[47] Folger R, Rodes J, Novak D. Bearing Killer: preventing common causes of bearing system damage part 1. Maintenance \& Engineering 2014; 14: 12-15.

[48] Jacobs W, Van Hooreweder B, Boonen R, Sas P, Moens D. The influence of external dynamic loads on the lifetime of rolling element bearings: Experimental analysis of the lubricant film and surface wear. Mechanical Systems and Signal Processing 2016; 74: 144-164.

[49] Collins D. What is L10 life and why does it matter? http://www.linearmotiontips.com/what-is-l10-lifeand-why-does-it-matter/; 2017 [Accessed 12 October 2017].

[50] Moubray J. Reliability-centred maintenance. Second Edition. Butterworth-Heinemann, Oxford; 1997.

[51] Mkandawire BO, Ijumba N, Saha A. Transformer risk modelling by stochastic augmentation of reliability-centred maintenance. Electric power systems research 2015; 119: 471-477.

[52] Wang W, Wang H. Preventive replacement for systems with condition monitoring and additional manual inspections. European Journal of Operational Research 2015; 247: 459-471.

[53] Harrell C, Ghosh BK, Bowden RO. Simulation using ProModel. Third Edition. McGraw Hill; 2011.

[54] Boylan J. Reproducibility. IMA Journal of Management Mathematics 2016; 27: 107-108.

[55] Law AM. Simulation Modelling and Analysis. Fifth edition. McGraw-Hill: New York; 2015.

[56] Robinson S. Simulation: The practice of model development and use. Wiley, New York, 2004.

[57] Banks J. Discrete-event System Simulation. Upper Saddle River: Pearson; 2010.

[58] ProModel. SimRunner User Guide. ProModel Corporation; 2010.

[59] Kim WK, Yoon KP, Kim Y, Bronson GJ. Improving system performance for stochastic activity network: A simulation approach. Computers \& Industrial Engineering 2012; 62: 1-12. 
Appendix 1. Flowchart of the general simulation procedure, showing the flow of entities from one modelling routine to another.

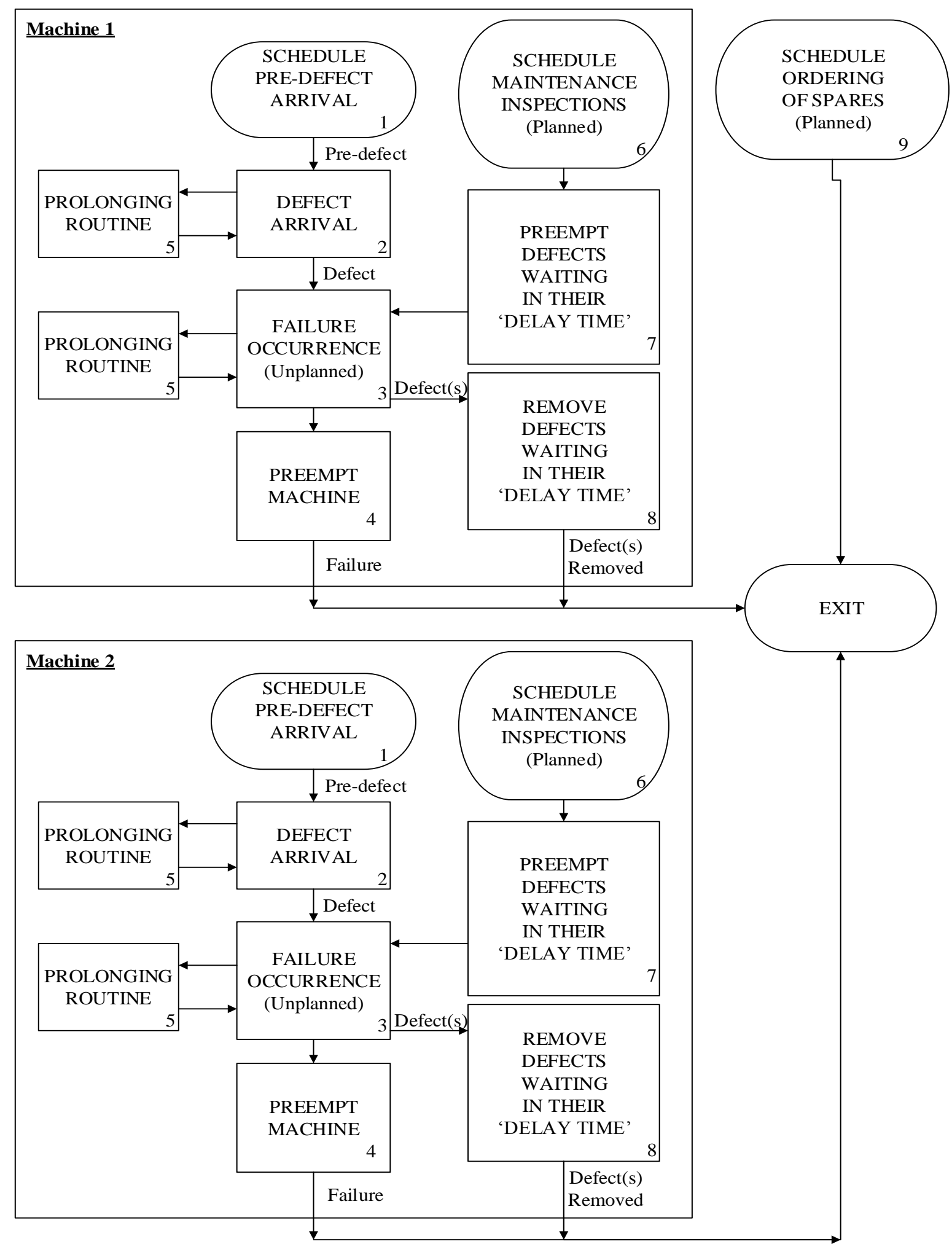


Appendix 2. Flowchart of the planned (scheduled) downtime routine for each machine.

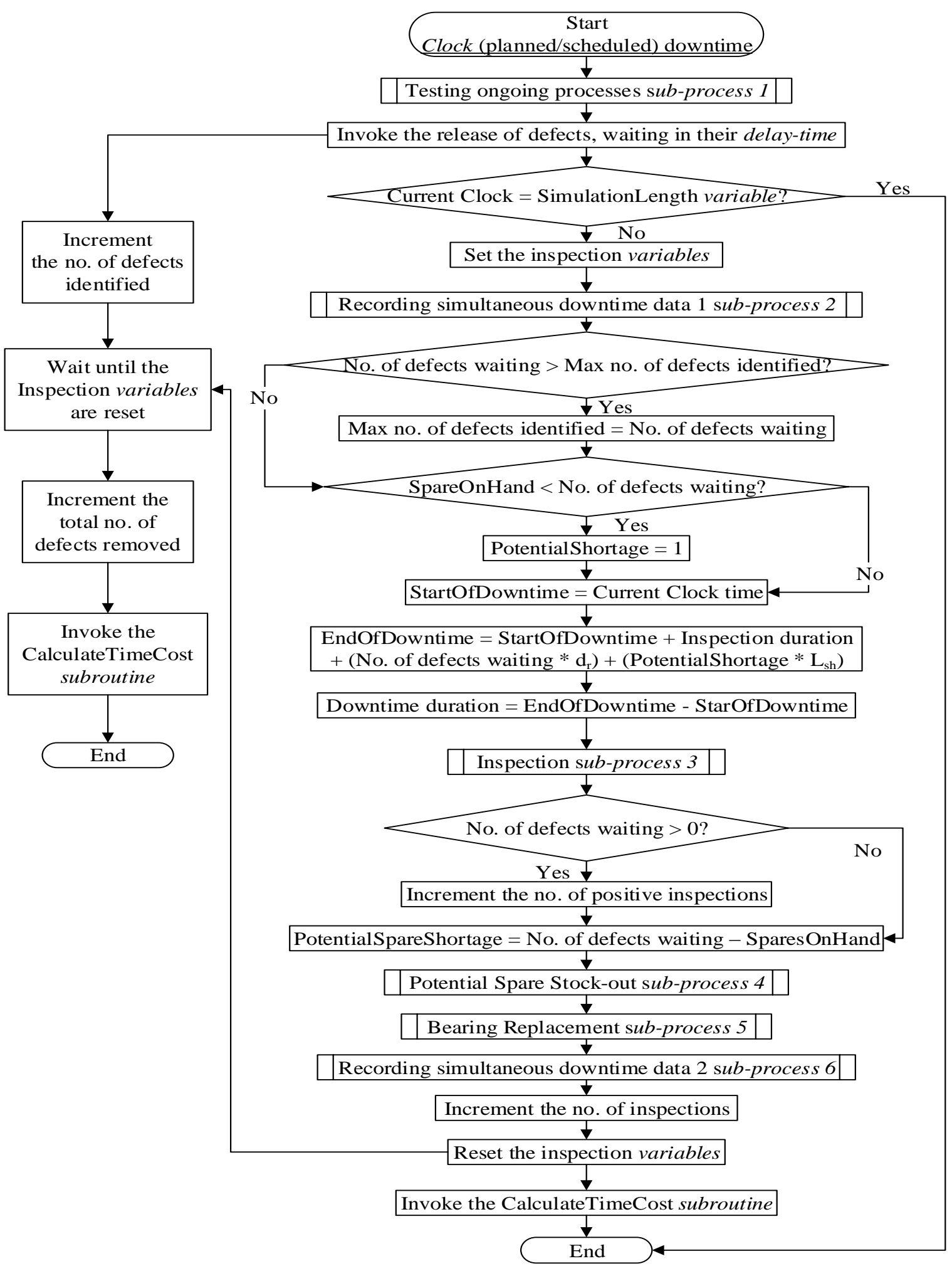


Appendix 3. Flowchart of the planned (scheduled) downtime sub-processes 1, $2 \& 6$ routines for each machine.
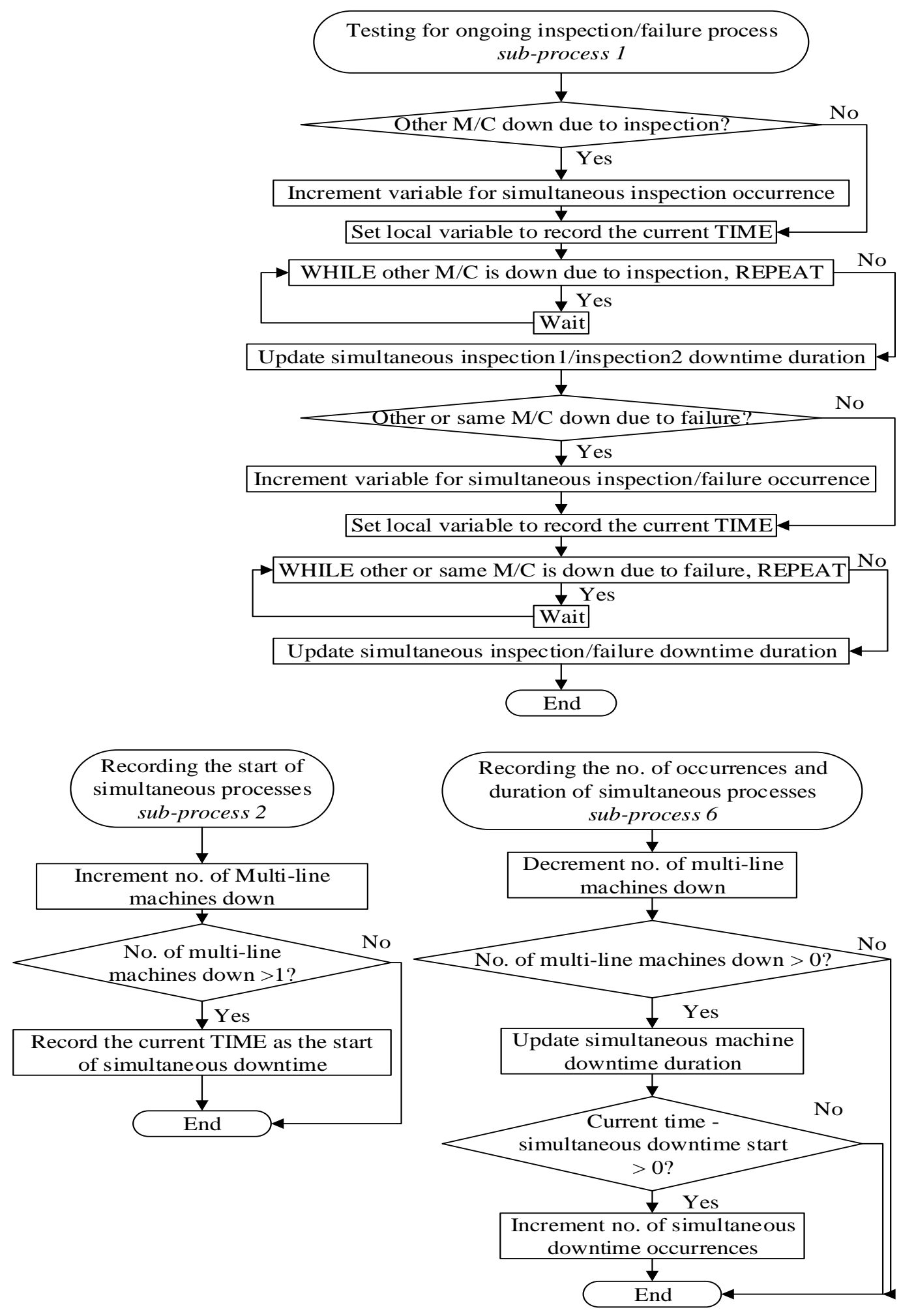
Appendix 4. Flowchart of the planned (scheduled) downtime sub-processes 3, $4 \& 5$ routines for each machine.
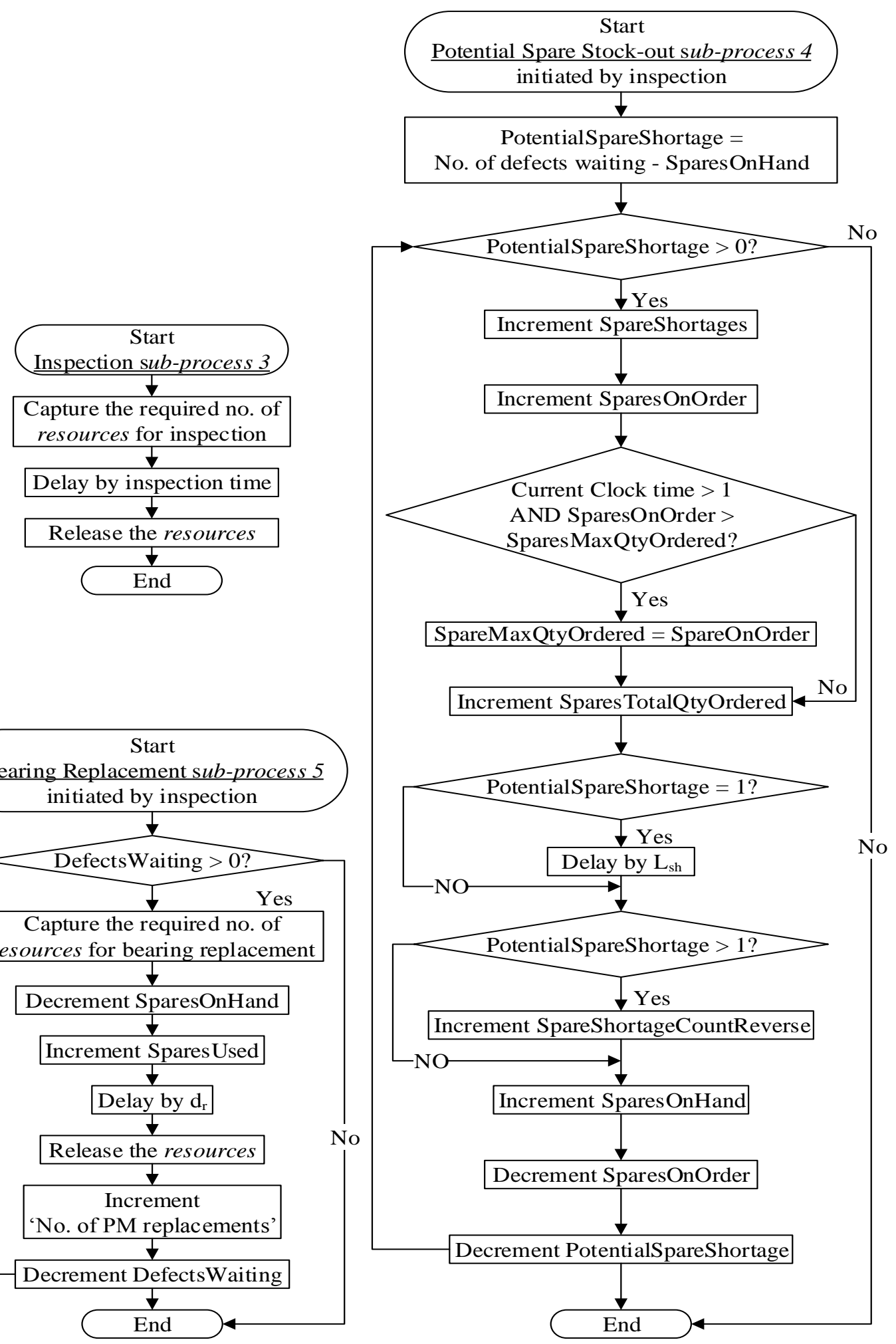